\title{
Perception of Institutional Quality as a Determining Factor in Academic Performance in Higher Middle School Students
}

\author{
A. E. Lima-Vargas ${ }^{1,2, *}$, A. Obaya ${ }^{3}$, S. Lima-Vargas ${ }^{1}$, M. R. Rosales-Soriano ${ }^{1}$ \\ ${ }^{1}$ Faculty of Accounting and Administration, National Autonomous University of Mexico, Coyoacan, Mexico City, Mexico. \\ ${ }^{2}$ Tlalnepantla Professional Academic Unit, Autonomous University of the State of Mexico, Tlalnepantla, State of Mexico, Mexico. \\ ${ }^{3}$ Chemical Sciences Department, Faculty of Higher Studies, Cuautitlan-National Autonomous University of Mexico, Cuautitlan \\ Izcalli, State of Mexico, Mexico.
}

How to cite this paper: A. E. Lima-Vargas, A. Obaya, S. Lima-Vargas, M. R. Rosales-Soriano. (2021). Perception of Institutional Quality as a Determining Factor in Academic Performance in Higher Middle School Students. The Educational Review, USA, 5(2), 17-26.

DOI: 10.26855/er.2021.02.001

Received: January 23, 2021

Accepted: February 18, 2021

Published: March 1, 2021

Corresponding author: A. E. Lima-Vargas, Faculty of Accounting and Administration, National Autonomous University of Mexico, Coyoacan, Mexico City, Mexico; Tlalnepantla Professional Academic Unit, Autonomous University of the State of Mexico, Tlalnepantla, State of Mexico, Mexico.

Email: alvarolimavargas@gmail.com

\begin{abstract}
Higher middle education is within compulsory education in most Latin American countries. In Mexico, higher middle education presents the lowest indicator in relation to terminal efficiency, this is due to the low academic performance of students. Meeting student expectations have been found to have a direct influence on their academic performance. Other authors indicate that the measurement of satisfaction in education should be considered from a service perspective. The study aims to assess the impact of students' perception of quality towards their institution (teachers and administrators) on their academic performance and gender differences. This study was conducted using the SERVQUAL data collection tool, in upper middle-level students in Mexico. The findings suggest that the ability to convey confidence during teacher-student or institution-student interaction is the variable that most influences students' academic performance, followed by tangibility and empathy with significant variations in gender. These results will help higher middle-level educational institutions develop not only educational plans, but also more efficient administrative plans to improve academic performance.
\end{abstract}

\section{Keywords}

Higher Middle Education, Student Satisfaction, Academic Performance, Perception of Institutional Quality

\section{Introduction}

In most Latin American countries, compulsory education comprises three levels of education: basic education, middle education, and higher middle education. Except for countries such as Colombia, El Salvador, Panama, and Guatemala where compulsory education has only of two levels of education, basic education, and middle education (SITEAL, 2019). In Mexico, it consists of four levels; basic (primary), middle (secondary), higher middle (high school), and higher (university). Having as compulsory education basic education, middle education, and higher middle education, as in most Latin American countries (SITEAL, 2019). On its part, higher middle education is segmented into three school cycles lasting one year, starting at 15 years, and ending at 18 years (INEE, 2019). This level of education is fundamental in professional development, since during this stage students will define their objectives and expectations related to their future. Being the main uncertainty for students, what will be the next step when finishing higher middle 
education. This situation can be summed up in to two alternatives, continue their education by accessing higher education or joining the labor market (Ochoa \& Diez-Martínez, 2009).

In most cases, the low academic performance of students in higher middle education, coupled with their low level of knowledge, poor advice on professional planning and scare university educational offering in Latin American countries, makes it difficult for students to access higher education, forcing them to join the labor market and in some cases to drop out of their studies (Martínez, 2002; Muñoz, 2001). In Mexico, this situation is represented by the terminal efficiency rate. Being higher middle education the one that has the lowest rate of all compulsory education in Mexico with a difference of $20 \%$ less than the other levels. As an example, in 2016, the terminal efficiency rate in basic education was $98 \%$, in middle education of $87 \%$ and in higher middle education of $65 \%$ (INEE, 2019). Good academic performance in higher middle education is essential to facilitate access to higher education in Mexico. For its part, a good academic performance is linked to study habits (Perez-Rivero et al., 2019) defining the latter as the techniques employed by students to acquire the knowledge provided in the most appropriate way to their characteristics (Morales et al., 2020).

During adolescence aspects such as laziness, disinterest and apathy are common, this coupled with low yield, lack of opportunity and low compliance with institutional expectations, cause personal dissatisfaction. All these lead students to academic demotivation. The loss of student motivation can be attributed to several elements being the main one the educational institution (Wilder, 2014).Some authors consider motivation as a fundamental element in the development of study habits and in the levels of educational adaptation by the student (Simons-Morton \& Chen, 2009). In addition, motivation will influence the students' school involvement, this being the level of commitment that the student will make with their institution and with their education (Djambazova-Popordanoska, 2016). These motivations can be classified into two items: extrinsic and intrinsic motivations (Cook \& Artino 2016). Being the extrinsic motivation, those generated by the environment through an incentive or a sanction (Espinar \& Ortega, 2015). In this sense, family and educational institution are the main extrinsic motivators of the student, through the participation and accompaniment of the student during the educational process (Zhan, 2006).

Intrinsic motivations, as the name implies, are generated by the psychological processes of the student (Espinar \& Ortega, 2015). Considering the satisfaction of students' quality expectations for their school, as one of the main factors in the student's intrinsic motivation, which will be reflected in higher academic performance by students (Galindo \& Sheldon, 2012). Current research on student motivation presented at various educational levels, have mostly focused on two aspects, the first being extrinsic motivation, where they particularly focus on identifying the external aspects that motivate the student. Where family and teachers are extrinsic motivators in middle higher education. Another is the intrinsic motivation in association with various constructs. These include emotional intelligence, academic performance, the choice of higher education, among others (Wilder, 2014).

This type of studies focused on intrinsic motivation, rarely present the perspective of Galindo and Sheldon (2012). Depending on the fact that motivation is generated by the satisfaction of quality expectations of students by the school as a consumer of a service. Students' appreciation of the school is essential when measuring the quality of teaching. Therefore, cultural activities, sport activities and student support are paramount in educational environments (Reichert $\&$ Print, 2018). About meeting the quality expectations of students Dursun, Oskayba, and Gokmen (2014) postulate the suitability of administrative models of quality perception. Because of its structure focused on a global service. Among the most cited models is the Service Model of Eiglier and Langerard (1993), which identifies quality as meeting user needs. Another is the model of the three components of Rust and Oliver (1994), which defines three aspects of quality: service, delivery, and environment.

For this work the most appropriate model is the SERVICE QUALITY (SERVQUAL) of Parasuraman, Zeithaml, and Berry (1985), under which it is consider the perception of quality as the satisfaction of the expected expectations of said service (Claver, Llopis, \& Tarí, 1999), and that its model can quantify the perception of quality of each user, considering their individual expectations in relation to the service. Being the most accurate model for mediating the variability of educational expectations at a level as complex as higher middle education due to its heterogeneity.

In relation to education, SERVQUAL has been applied in countries such as Malaysia (Fitri, Ilias, Abd, \& Zulkeflee, 2008), Turkey (Dursun, Oskayba, \& Gokmen, 2014) and Slovenia (Faganel, 2010). In Latin America, it has been used at the University of Cartagena, Colombia (Vergara \& Quesada, 2011), at the University of Carabobo in Venezuela (Mejías, Teixeira, Rodríguez, \& Arzola, 2010), among others. Obtaining positive results determine the perception of quality of students in relation to educational services. However, it has not been related to academic performance.

The SERVQUAL model considers five differences between service expectations and the service provided by the organization in this case the school, these differences take the name GAP (Parasuraman, Zeithaml, \& Berry, 1985). The first GAP considers students' perceptions of whether the school perceives the student's expectations about it. The 
second GAP contemplates students' perception of whether the school is integrating the student's expectations into the service. The third GAP considers students' perception of whether the service provided correctly integrates student's expectations. The fourth GAP assesses students' perception of whether the school's promotion or communication of services is consistent with the service it provides. The fifth GAP analyzes students' perception of the service received by the school, in contrast to the expected service. Being the expectations of the expected service generated by what is promised by the school, personal needs, previous experiences, and other factors of the environment.

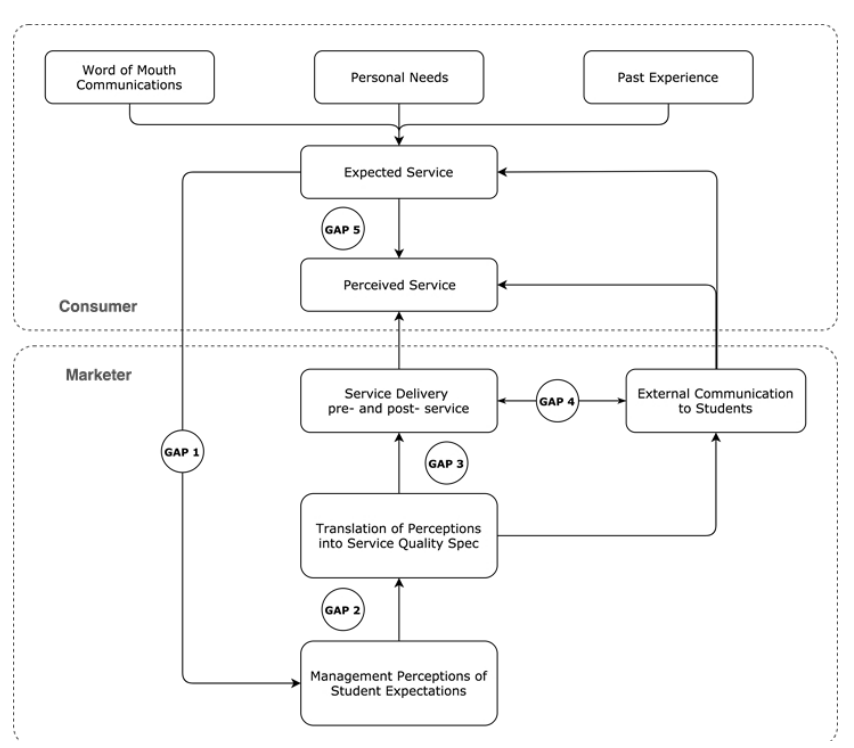

Figure 1. Model Quantifies GAP on a 5-dimensional scale, covering tangible, empathy, reliability, responsiveness, and assurance.

This model quantifies GAP on a 5-dimensional scale, covering tangible, empathy, reliability, responsiveness, and assurance (Figure 1). The model applied in education is considered as follows:

1) Tangible refers to the physical facilities, equipment, and materials of the educational institution, as well as the appearance of the staff (teachers and administrative).

2) Empathy alludes to the individualized care the student receives from the teacher and the school.

3) Reliability refers to teachers and administrators' skills in performing their duties in an appropriate manner to meet the student's expectations at the agreed time.

4) Responsiveness, which considers the willingness to serve of teachers and administrators within the school.

5) Assurance, which contemplates the ability to convey trust during teacher-student or institution-student interaction.

This study aims to identify whether the satisfaction of students' expectations by the educational institution will be reflected in higher academic performance. Quantifying expectations from an administrative perspective, using SERVQUAL model where quality perception is defined as meeting expectations.

\section{Method}

\subsection{Type of research}

The methodology of the study is quantitative. In reference to the way the data is processed, it is defined as correlational-causal. Also, it has a non-experimental-observational cross-sectional approach in relation to the collecting of data (Niu, 2020).

\subsection{Study participants}

Study participants are students enrolled in higher middle school. With an age range between 15 and 18 years, without distinction of gender, residents of the Valley of Mexico (Mexico City and State of Mexico). According to the INEE National Census there are currently more than one million students with these characteristics in the Valley of México (INEE, 2019). 


\subsection{Measurement parameters}

A two-stage data collection tool was developed to gather the information for the study. The first section with 5 multiple choice questions delimits the basics of respondents such as age, gender, academic performance, current educational enrollment, and place of residence. For the parameters of the study, criteria were established in the questions of; age (where if the answer was between 15 and 18 years old, they could continue with the next question), place of residence (where if the answer was Mexico City or State of Mexico, they could continue with the next question) finally in the current educational adscription (if the answer is higher middle education, they could continue to complete the instrument).

The second section corresponds to the quantification of student expectations satisfaction, the SERVQUAL model was integrated by 22 items (Table 1) measuring tangibility, reliability, responsiveness, assurance, and empathy. With a 5-point Likert scale (in which 1 corresponds to "Completely disagree" and 5 to "Totally Agree").

Table 1. The SERVQUAL instrument (Quantification of student expectation satisfaction)

\begin{tabular}{|c|c|}
\hline Construct & Items \\
\hline \multirow{4}{*}{ Tangible } & 1. The school should have up to date physical facilities. \\
\hline & 2. Their physical facilities should be visually appealing. \\
\hline & 3. The teachers and administrative staff should be well dressed and appear neat. \\
\hline & 4. The appearance of the furniture and materials should be visually appealing \\
\hline \multirow{5}{*}{ Reliability } & $\begin{array}{l}\text { 5. When teachers and administrative staff from your school promise to do something by a certain time, } \\
\text { they should do so. }\end{array}$ \\
\hline & $\begin{array}{l}\text { 6. When students have problems, teacher and administrative staff should be sympathetic and reassuring } \\
\text { to find a solution. }\end{array}$ \\
\hline & 7. Teachers and administrative staff should get their services done right the first time. \\
\hline & 8. Teachers and administrative staff should provide their services at the time they promise to do so. \\
\hline & 9. Teachers and administrative staff should always seek not to make mistakes. \\
\hline \multirow{4}{*}{ Responsiveness } & 10. Administrative staff should tell the students when the performance of the services will end. \\
\hline & 11. School's Administrative staff should give a fast service to its students. \\
\hline & 12. Teachers and administrative staff must be willing to help students. \\
\hline & 13. Teachers and administrative staff should not be too busy to respond students' requests promptly. \\
\hline \multirow{4}{*}{ Assurance } & 14. Teachers and administrative staff behavior should build towards students \\
\hline & 15. Students should be able to feel safe in their transactions with teachers and administrative staff. \\
\hline & 16. Teachers and administrative staff should be polite towards students. \\
\hline & 17. Teachers and administrative staff have the adequate knowledge to answer students' questions. \\
\hline \multirow{5}{*}{ Empathy } & 18. Teachers and administrative staff should be expected to give students individual attention. \\
\hline & $\begin{array}{l}\text { 19. Teachers and administrative staff should have adequate work hours to give personal attention to the } \\
\text { students. }\end{array}$ \\
\hline & 20. Teachers and administrative staff offer students individual attention. \\
\hline & 21. Teachers and administrative staff should have their students' best interest and needs at heart \\
\hline & 22. Teachers and administrative staff are expected to understand students' specific needs. \\
\hline
\end{tabular}

Source: Instrument for data collection adapted from SERVQUAL's Instrument. Own elaboration.

\subsection{Data collection and processing}

The appropriate sample size for the study was determined using the sample size formula for a finite population (Laurencelle, 2009; Niu, 2020), with a known population of 1 million participants, a confidence level of 95\%, an error of $5 \%$ and a probability $p$ of 0.5 . Obtaining an estimated sample of $n=385$. Equation (1)

$$
n=\frac{N * Z^{2} * p * q}{d^{2} *(N-1)+Z^{2} * \mathrm{p} * q}
$$

Equation 1. Sample size for finite population. Where $N$ is the known population, $Z$ the confidence level, $d$ the error, $p$ 
the probability of success, $q$ the probability of failure and $n$ the acceptable sample size.

Following the application of the instrument, a total of 482 questionnaires were obtained, of which 39 had filling errors (incomplete, poorly filled or does not meet study parameters), giving a total of 443 valid instruments, providing reliability to the study.

To identify the statistical reliability of the collected data, the instrument was initially analyzed using a Cronbach Alpha. Equation (2). Each variable was then analyzed (tangible, empathy, reliability, responsiveness, assurance), defining as an acceptance parameter for the study a $\alpha>0.8$ (Laurencelle, 2009). If the values are less than the acceptance parameter, the study variable is deleted.

$$
\alpha=\frac{K}{K-1}\left[1-\frac{\sum S_{i}^{2}}{S_{T}{ }^{2}}\right]
$$

Equation 2. Cronbach Alpha. Where $\alpha$ is that of Cronbach's alpha; $S^{2}$ represents the sum of the variances of each item, $S_{T}^{2}$ represents the total variance, and $K$ indicates the number of items.

To check the relationship between variables and academic performance, linear regression was used for each of the study variables. In addition, a Pearson correlation Equation (3) was applied as statistical support. Acceptance parameters, for multiple linear regression $\mathrm{R}^{2}>0.6$ and for Pearson correlation of $\mathrm{r}>0.7$

$$
\mathrm{r}=\frac{S_{x y}}{S_{x} * S_{y}}
$$

Equation 3. Pearson correlation. $r$ corresponds to the symbol of Pearson's linear correlation, $S_{\mathrm{x}}$ is the typical deviation of $x$, and $S_{Y}$ that of $y$ and $S_{x y}$ is the covariance between $x$ and $y$.

To remove errors in the calculation of multiple linear regression, multicollinearity was calculated in the study variables. Multicollinearity was estimated by a Kendal Tau Equation (4) (Laurencelle, 2009). The acceptance parameter for Kendal $\mathrm{Tau}$ is $\mathrm{Tb}>0.8$.

$$
\mathrm{T}_{b}=\frac{P-Q}{\sqrt{\left(P+Q+X_{0}\right)\left(P+Q+Y_{0}\right)}}
$$

Equation 4. Tau by Kendal. Where $X_{0}$ is related only in variable $X, Y_{0}$ is related in the variable $Y$, Tb is the Tau symbol of Kendal, $P$ is the number of matching pairs, and $Q$ is the number of discordant pairs.

\section{Results and discussion}

\subsection{Results}

Study sample data from respondents showed that the percentage of women was $62.9 \%$, compared to men $37.1 \%$. In relation to the school year, $28.67 \%$ of students reported to be enrolled in their first year of higher middle education, $39.05 \%$ in the second year and $32.28 \%$ in their third year. Finally, regarding academic performance, the results indicated that $23.03 \%$ averages between 6.00 and $6.99,30.25 \%$ between 7.00 and $7.99,28.44 \%$ between 8.00 and 8.99 and $18.28 \%$ between 9.00 and 10.00 (Table 2 ).

Table 2. Study sample data

\begin{tabular}{ccc}
\hline & Amount & Percentage \\
\hline Gender & 443 & 100 \\
Men & 164 & 62.9 \\
Women & 279 & 37.1 \\
& & \\
School Year & 443 & 100 \\
1 & 127 & 28.67 \\
2 & 173 & 39.05 \\
3 & 143 & 32.28 \\
& & \\
Average & 443 & 100 \\
6.00 to 6.99 & 102 & 23.03 \\
7.00 to 7.99 & 134 & 30.25 \\
8.00 to 8.99 & 126 & 28.44 \\
9.00 to 10.00 & 81 & 18.28 \\
\hline
\end{tabular}

Source: Own elaboration with SPSS data. 
The calculation of validity of the data using Cronbach Alpha determined that the data collected is valid with an Alpha of 0.841 . In addition, the results of the variables showed that tangible has an alpha of 0.824 , the reliability of 0.878 , the response capacity of 0.896 , the assurance of 0.826 , the empathy of 0.831 and the academic performance of 0.813 . Placing the variables into an acceptance parameter according to the study indicators for the Cronbach Alpha. Therefore, all variables are eligible for subsequent analyses (Table 3).

Table 3. Validation of evaluation instrument: Cronbach Alpha results

\begin{tabular}{cc}
\hline Construct & Cronbach Alpha if the item has been deleted \\
\hline Instrument & 0.841 \\
Academic performance & 0.813 \\
Tangible & 0.824 \\
Empathy & 0.878 \\
Reliability & 0.896 \\
Responsiveness & 0.826 \\
Assurance & 0.831 \\
\hline
\end{tabular}

Source: Own elaboration with SPSS data.

Multicollinearity estimated the associations between independent variables (tangible, reliability, responsiveness, assurance, empathy, and academic performance). Obtaining the most significant results between tangible and empathy with a collinearity of 0.645 , which, in relation to the parameters of the study, is not considered significant. In addition, tangible and assurance have a collinearity of 0.640 which are not considered significant either. Therefore, the results obtained in linear regression should not be affected by the relationship of independent variables (Table 4).

Table 4. Multicollinearity analysis

\begin{tabular}{|c|c|c|c|c|c|}
\hline Construct & Tangible & Reliability & Responsiveness & Assurance & Empathy \\
\hline Tangible & 1 & & & & \\
\hline Reliability & 0.356 & 1 & & & \\
\hline Responsiveness & 0.275 & 0.181 & 1 & & \\
\hline Assurance & 0.640 & 0.483 & 0.207 & 1 & \\
\hline Empathy & 0.645 & 0.358 & 0.214 & 0.559 & 1 \\
\hline
\end{tabular}

Source: Own elaboration with SPSS data.

Multiple linear regression results for variable analysis showed that tangibility positively influences students' academic performance $\left(\mathrm{R}^{2}=0.677\right.$, Pearson correlation coefficient of 0.840$)$. Therefore, tangibility is considered to influence students' academic performance at the higher middle level. Specifically, in the case of gender, women $\left(\mathrm{R}^{2}=0.759\right.$, Pearson correlation coefficient of 0.871$)$ are more susceptible than men $\left(\mathrm{R}^{2}=0.670\right.$, Pearson correlation coefficient of 0.819 ) to be influenced on their academic performance (Table 5).

Table 5. Tangible, Linear regression analysis results

\begin{tabular}{cccccc}
\hline Variable Independent & $\mathrm{R}^{2}$ & $\mathrm{R}^{2}$ Adjusted & Pearson correlation & Standard estimation error & Non-standardized Beta coefficients \\
\hline Tangible & 0.721 & 0.720 & 0.849 & 0.547 & 0.586 \\
Women & 0.759 & 0.758 & 0.871 & 0.498 & 0.572 \\
Men & 0.670 & 0.668 & 0.819 & 0.607 & 0.607 \\
\hline
\end{tabular}

Note: The dependent variable is Academic performance. Source: Own elaboration with SPSS data.

In contrast, the results indicated that reliability does not influence students' academic performance $\left(\mathrm{R}^{2}=0.404\right.$, Pearson correlation coefficient of 0.636). In regard to gender, neither female $\left(\mathrm{R}^{2}=0.407\right.$, Pearson correlation coefficient of 0.640$)$, nor men $\left(\mathrm{R}^{2}=0.408\right.$ Pearson correlation coefficient of 0.642$)$ showed acceptable indicators. It is therefore determined that reliability is not representative in academic performance at higher middle level (Table 6). 
Table 6. Reliability, Linear regression analysis results

\begin{tabular}{cccccc}
\hline Variable Independent & $\mathrm{R}^{2}$ & $\mathrm{R}^{2}$ Adjusted & Pearson correlation & Standard estimation error & Non-standardized Beta coefficients \\
\hline Reliability & 0.404 & 0.403 & 0.636 & 0.800 & 0.425 \\
Women & 0.409 & 0.407 & 0.640 & 0.780 & 0.455 \\
Men & 0.412 & 0.408 & 0.642 & 0.811 & 0.389 \\
\hline
\end{tabular}

Note: The dependent variable is Academic performance. Source: Own elaboration with SPSS data.

In addition, the responsiveness' analysis determines that it has no impact on academic performance. Linear regression results indicated an $\mathrm{R}^{2}=0.046$ and a Pearson correlation coefficient of 0.219 . Gender analysis also pointed out that there is no relationship between responsiveness and academic performance of women with an $\mathrm{R}^{2}=0.094$ and a Pearson correlation of 0.311 , compared to that of men who had an $\mathrm{R}^{2}=0.005$ and a Pearson correlation of 0.104 (Table 7).

Table 7. Responsiveness, Linear regression analysis results

\begin{tabular}{cccccc}
\hline Variable Independent & $\mathrm{R}^{2}$ & $\mathrm{R}^{2}$ Adjusted & Pearson correlation & Standard estimation error & Non-standardized Beta coefficients \\
\hline Responsiveness & 0.048 & 0.046 & 0.219 & 1.011 & 0.249 \\
Women & 0.097 & 0.094 & 0.311 & 0.965 & 0.333 \\
Men & 0.011 & 0.005 & 0.104 & 1.052 & 0.133 \\
\hline
\end{tabular}

Note: The dependent variable is Academic perform0.046ance. Source: Own elaboration with SPSS data.

While the relationship between assurance and academic performance showed results of an $\mathrm{R}^{2}=0.746$ and a Pearson correlation of 0.864 . These results allow to determine the existence of a correlation between the variables assurance and academic performance. Gender analysis presented results in relation to men of an $\mathrm{R}^{2}=0.737$ and a Pearson correlation of 0.858 , and for women a $\mathrm{R}^{2}=0.750$ and a Pearson correlation of 0.866 . Gender outcomes determined greater influence on women, however, the difference is not significant. Therefore, it can be said that the more perception of quality in the assurance of the school, the greater academic performance by students (Table 8).

Table 8. Assurance, Linear regression analysis results

\begin{tabular}{cccccc}
\hline Variable Independent & $\mathrm{R}^{2}$ & $\mathrm{R} 2$ Adjusted & Pearson correlation & Standard estimation error & Non-standardized Beta coefficients \\
\hline Assurance & 0.746 & 0.745 & 0.864 & 0.522 & 0.735 \\
Women & 0.750 & 0.749 & 0.866 & 0.507 & 0.764 \\
Men & 0.737 & 0.735 & 0.858 & 0.542 & 0.691 \\
\hline
\end{tabular}

Note: The dependent variable is Academic performance. Source: Own elaboration with SPSS data.

Finally, the results revealed that the perception of quality in empathy directly influences academic performance. The linear regression analysis had a value of $\mathrm{R}^{2}=0.669$ and a Pearson correlation of 0.818 . In contrast, the results in relation to men had a value of $\mathrm{R}^{2}=0.500$ and a Pearson correlation of 0.707 , unlike women who had a value of $\mathrm{R}^{2}=0.787$ and a Pearson correlation of 0.887 . Given the above, it can be established that the relationship is valid only for women (Table 9).

Table 9. Empathy: Linear regression analysis results

\begin{tabular}{cccccc}
\hline Variable Independent & $\mathrm{R}^{2}$ & $\mathrm{R}^{2}$ Adjusted & Pearson correlation & Standard estimation error & Non-standardized Beta coefficients \\
\hline Empathy & 0.699 & 0.668 & 0.818 & 0.596 & 0.638 \\
Women & 0.787 & 0.786 & 0.887 & 0.469 & 0.684 \\
Men & 0.500 & 0.497 & 0.707 & 0.747 & 0.555 \\
\hline
\end{tabular}

Note: The dependent variable is Academic performance. Source: Own elaboration with SPSS data.

\subsection{Discussion}

In relation to tangible variable and academic performance, the results of linear regression indicate that a greater perception of quality in educational tangibility generates greater academic performance on the part of students. It should be noted that the analysis reveals that women are more likely than men to improve their academic performance in 
relation to a higher quality perception in tangibility. Under this approach, several factors can explain the relationship between meeting tangible expectations and academic performance. For example, a greater perception of the quality of educational facilities will motivate the students in their academic activity, thus improving academic performance.

Reliability-related results indicate that administrative capabilities and teachers within the school are not an influencing factor on academic performance. A plausible explanation is that the age of students at this education level means that they are mostly influenced by emotional factors (Reichert \& Print, 2018). Therefore, factors such as empathy on the part of teachers and administrators are elements more relevant to student motivation than teacher's abilities.

There is no relationship between the student's perception of teacher quality and academic performance, although a teacher quality assessment system by students will increase students' academic performance.

The results of responsiveness and academic performance denote that a great will for service by teachers and administrative staff is not a relevant variable in academic performance. However, studies such as Zhan's (2006) shows that higher performance by the teacher will influence students' academic performance. In this sense, it is essential to remember that the quantification of variables is made in relation to the perception of student quality. Therefore, it is considered that the results do not differ from those proposed by Zhan (2006). Adding that the satisfactions of expectations of institutional responsiveness are considered as the will of service by teachers and administrative staff which do not influence the academic performance of the student.

In contrast, assurance outcomes showed that academic performance and the ability to convey trust are correlated variables. One explanation is that emotional factors are mostly influenced by the confidence conveyed in teacher-student and institution-student interaction. This transmission of confidence in emotions generates a change in student's motivations by improving their academic performance (Cook \& Artino, 2016). It should be noted that this variable is equally significant for both men and women.

Finally, based on linear regression coefficients, findings indicate that empathy is a fundamental element in academic performance. However, this link is only valid for women, as men's academic performance is not influenced by teaching or administrative empathy. This can be explained, due to emotional control (emotional intelligence), which is greater in women than in men (Faganel, 2010). It is therefore more difficult for man to consider empathy as a motivator within teaching or administrative expectations.

\section{Conclusions and repercussions}

In the academic field the aspects of student motivation are broad in literature, however, the aspects of intrinsic motivation in higher middle education are scarce, mostly in higher middle education in Mexico. And they are even more so when they focus on meeting student expectations and relate it to academic performance. This is represented by a few satisfaction studies that consider the perspective of Galindo and Sheldon (2012), in relation to the fact that meeting student's expectations will improve academic performance. There are several approaches on how to accurately measure student satisfaction through teacher quality, educational quality, or institutional quality. Considering in most studies only one spectrum in student satisfaction, in this sense, Wilkins and Balakrishnan (2013) consider when quantifying student satisfaction is relevant to do so from an administrative perspective of service, as seeing the student as a consumer of services. Within the administrative service models SERVQUAL is considered one of the most complete by virtue of understanding the service as a whole.

Hence this study is important, since it links two untreated perspectives in academic literature, through the application of SERVQUAL to identify the perception of quality of students correlating them with academic performance at a higher middle educational level in Mexico. Among the most important findings is that a greater perception of quality in assurance, understanding this as the trust that the school and the teacher transmit to students. It is the element that influences students' academic performance the most, without showing a gender distinction. In contrast the perception of teaching abilities or institutional capacity will not have impact on academic performance. In addition, the empathy by the educational institution and teachers directly influences the academic performance of women.

This research provides empirical evidence focused on improving academic performance from an institutional service perspective, giving answers to the question of "Which institutional aspects have a greater impact on the student's motivation and thus their academic performance?" The objective of this research is to provide support for the teaching-administrative decision-making in relation to the service, when structuring work plans and operational budgets. Additionally, this study contributes to academic literature by focusing on an undertreated area such as the service approach on academic performance in higher middle education in Mexico. This is relevant, as few studies have focused on quantifying the satisfaction of student expectations as a service, quantifying it from an administrative perspective, achieving favorable results. 


\section{Acknowledgements}

This work was supported by UNAM-PAPIME $<$ PE308920 $>$.

Investigación realizada gracias al Programa UNAM-PAPIME $<$ PE308920 $>$.

\section{References}

Claver, E., Llopis, J., and Tarí, J. (1999). Quality and Business Management. Madrid: CivitasEconomics and Business Library, Business Collection.

Cook, D. and Artino, A. (2016). Motivation to learn: an overview of contemporary theories. Med Educ., 50(10): 997-1014. DOI: https://doi.org/10.1111/medu.13074.

Djambazova-Popordanoska, S. (2016). Implications of emotion regulation on young children's emotional wellbeing and educational achievement. Educational Review, 68(4), 497-515. DOI: https://doi.org/10.1080/00131911.2016.1144559.

Dursun, T., Oskayba, K., and Gokmen, C. (2014). Perceived quality of distance education from the user perspective. Contemporary Educational Technology, 5, 121-145.

Eiglier, P. and Langeard, E. (1993). Service Model. Service marketing. McGraw-Hill. USA.

Espinar, R. and Ortega, J. (2015). Motivation: The Road to Successful Learning. Profile Issues in Teachers' Professional Development, 17(2), 125-136. DOI: http://dx.doi.org/10.15446/profile.v17n2.50563.

Faganel, A. (2010). Quality perception gap inside the higher education institution. International Journal of Academic Research, 2, 213-216.

FitriA, H., Ilias, A., Abd, R., and Zulkeflee, M. (2008). Service quality and student satisfaction: a case study at private higher education institutions. International Business Research, 1, 163-175.

Galindo, C. and Sheldon, S. (2012). School and home connections and children's kindergarten achievement: The mediating effects of family involvement'. Early Childhood Research Quarterly, 27(1), 90-103. DOI: https://doi.org/10.1016/j.ecresq.2011.05.004.

INEE. (2019). National Institute for the Evaluation of Education. Mexico. Inicio-INEE https://www.inee.edu.mx/medios/informe2019/stage_01/tem_05.html.

Laurencelle, L. (2009). Kendall's tau and tau b for the correlation of simple or categorical ordinal variables. Tutorials in Quantitative Methods for Psychology, V, 51-58.

Martínez, F. (2002). "New view of the country of inequality. The distribution of schooling in Mexico, 1970-2000." Mexican Journal of Educational Research, 7(6), 415-443.

Mejías, A., Teixeira, J., Rodríguez, J., and Arzola, M. (2010). Evaluation of the quality of non-academic university services in a Venezuelan university. Eighth LACCEI Latin American and Caribbean Conference for Engineering and Technology (LACCEI'2010) — “Innovation and Development for the Americas", 1-9.

Morales, A., Obaya, A., Montaño, C., and Vargas, Y. M. (2020). Exploratory Assessment of Strategy for Learning Redox Reactions in High School International Journal of Education (IJE). Vol. 8, No.1, 23-37. DOI: 10.5121 / ije.2020.8102.

Muñoz, C. (2001). "Education and economic and social development. Public policies in Mexico and Latin America during the last decades of the 20th century". Educational Profiles, 13(91), 7-36.

Niu, L. (2020). A review of the application of logistic regression in educational research: common issues, implications, and suggestions. Educational Review, 72(1), 41-67. DOI: https://doi.org/10.1080/00131911.2018.1483892.

Ochoa, A. and Diez-Martínez, E. (2009). Occupational aspirations in high school: A view from Educational Psychology. Educational Profiles, 31(125), 38-61. Recovered on July 01, 2020, from http://www.scielo.org.mx/scielo.php?script=sci_arttext\&pid= S0185-26982009000300004\&lng=es\&tlng=es.

Parasuraman, A., Zeithaml, V., and Berry, L. (1985). A conceptual model of service quality and its implications for future research. The Journal of Marketing, 49(4), 41-50. https://www.jstor.org/preview-page/10.2307/1251430?seq=1.

Perez-Rivero, M. G., Obaya, V. A., Giamatteo, L., Montaño-Osorio, C., Vargas-Rodríguez, Y. M. (2019). Didactic Strategy for Learning and Teaching of Functional Groups in High School Chemistry. Science Education International, 30(2), 85-91. DOI: 10.33828 / sei.v30.i2.1.

Reichert, F. and Print, M. (2018). Civic participation of high school students: The effect of civic learning in school, Educational Review, 70(3), 318-341. DOI: https://doi.org/10.1080/00131911.2017.1316239.

Rust, R. T. and Oliver, R. L. (1994). Service quality: New directions in theory and practice. Sage Publications.

Simons-Morton, B. and Chen, R. (2009). Peer and parent influences on school engagement among early adolescents. Youth and Society, 41(1), 3-25. doi: https://doi.org/10.1177/0044118X09334861. 
SITEAL. (2019). Educational Trend Information System in Latin America. SITEAL (unesco.org) https://www.inee.edu.mx/ medios/informe2019/stage_01/tem_05.html.

Vergara, J. and Quesada, V. (2011). Analysis of the quality in the service and satisfaction of the students of Economic Sciences of the University of Cartagena through a model of structural equations. Electronic Journal of Educational Research, 13, 108-122.

Wilder, S. (2014). Effects of parental involvement on academic achievement: a metasynthesis. Educational Review, 63(3), $377-397$. DOI: https://doi.org/10.1080/00131911.2013.780009.

Wilkins, S. and Stephens, B. M. (2013). "Assessing student satisfaction in transnational higher education". International Journal of Educational Management, Vol. 27, No. 2, pp. 143-156. https://doi.org/10.1108/09513541311297568.

Zhan, M. (2006). Assets, parental expectations and involvement, and children's educational performance. Children and Youth Services Review, 28, 961-975. DOI: https://doi.org/10.1016/j.childyouth.2005.10.008. 